\title{
MEASUREMENT OF FREQUENCY RESPONSE IN SHORT THERMOCOUPLE WIRES
}

Progress Report

May 1991 - October 1991

L. J. Forney

E. L. Meeks

J. Ma
$1 N-35-2$

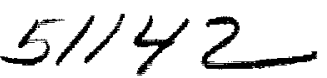

Georgia Institute of Technology

Atlanta, Georgia 30332

G. C. Fralick

NASA - Lewis Research Center

Cleveland, Ohio 44135

Sponsored by

\section{ARNOLD ENGINEERING DEVELOPMENT CENTER}

Arnold Air Force Base, Tennessee 37389

under

NASA Cooperative Agreement NCC 3-135

(NASA-CR-1\&78?1) MEASUREMENT OF FREQUENCY

RESPONSE IN SHORT THERMOCOUPLE WIRES

Progress Report, May - Oct. 1991 (Georgia

Inst. of Tech.) $29 \mathrm{p} C S C L 143$

CSCL 143 Unclas

N92-11339

G3/35 0051142

Georgia Institute of Technology

November, 1991 


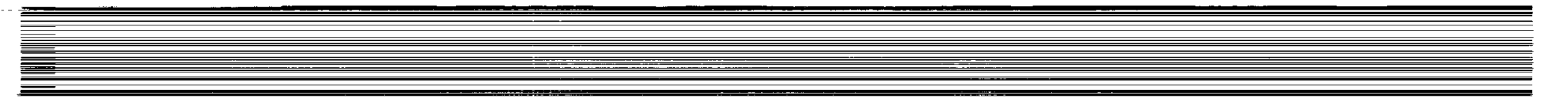

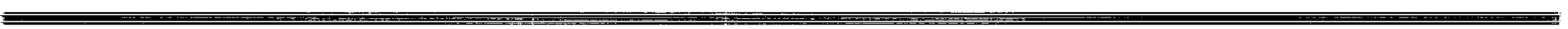

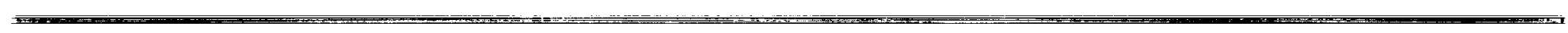


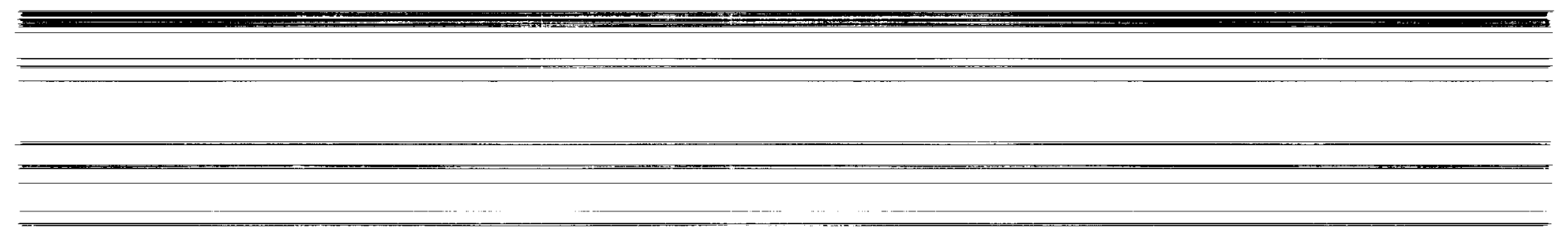

$\bar{\equiv}$

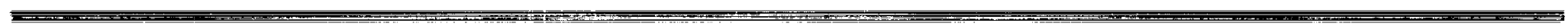
= ב

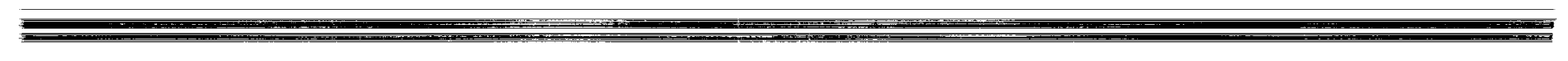
 


\title{
Measurement of Frequency Response in Short Thermocouple Wires
}

\author{
L. J. Forney ${ }^{1}$ \\ E. L. Meeks ${ }^{2}$ \\ J. $\mathrm{Ma}^{3}$ \\ Georgia Institute of Technology \\ Atlanta, Georgia 30332 \\ G. C. Fralick \\ NASA - Lewis Research Center \\ Cleveland, Ohio 44135
}

\footnotetext{
'School of Chemical Engineering

${ }^{2}$ Microelectronics Research Center

${ }^{3}$ School of Mechanical Engineering
} 


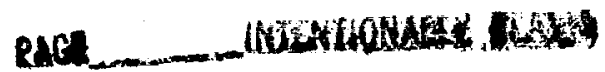




\begin{abstract}
Experimental measurements are made for the steady-state frequency response of a supported thermocouple wire. In particular, the effects of axial heat conduction are demonstrated for both a supported one material wire (type $\mathrm{K}$ ) and a two material wire (type $\mathrm{T}$ ) with unequal material properties across the junction. The data for the amplitude ratio and phase angle are correlated to within $10 \%$ with the theoretical predictions of Fralick and Forney (1991). This is accomplished by choosing a natural frequency $\omega_{n}$ for the wire data to correlate the first order response at large gas temperature frequencies. It is found that a large bead size, however, will increase the amplitude ratio at low frequencies but decrease the natural frequency of the wire. The phase angle data are also distorted for imperfect junctions.
\end{abstract}




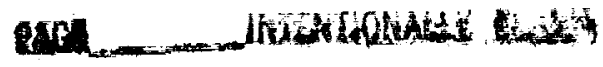

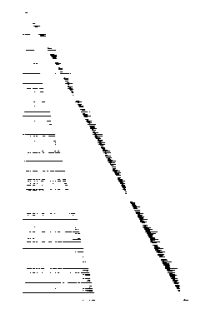




\section{INTRODUCTION}

The evaluation of jet engine performance and fundamental studies of combustion phenomena depend on the measurement of turbulent fluctuating temperatures of the gas within the engine (Dils and Follansbee, 1976). Historically, these temperatures have been measured with thermocouples. The advantages of thermocouples are their low cost, reliability and simplicity since they do not require optical access or elaborate support electronics. However, the design of a thermocouple represents a compromise between accuracy, ruggedness and rapidity of response.

For example, the measurement of fluctuating temperatures in the high speed exhaust of a gas turbine engine combustor is required to characterized the local gas density gradients or convective heat transfer (Fralick, 1985). Although thermocouples are suitable for the measurement of high frequency temperature fluctuations $(<1 \mathrm{KHz})$ in a flowing gas or liquid, the measured signal must be compensated since the frequency of the time dependent fluid temperature is normally much higher than the corner frequency of the thermocouple probe (Scadron and Warshawsky, 1952). Moreover, the amplitude and phase angle of the thermocouple response may be attenuated by axial heat conduction for rugged thermocouples of finite length (Elmore, et al.; 1983, 1986).

In the present study, measurements are made of the steady-state frequency 
response of supported thermocouple wires. In particular, the effects of axial heat conduction are demonstrated for both a supported one material wire and a two material wire with unequal material properties across the junction. The measurements are presented in the form of the amplitude ratio and phase angle and these data are compared with the recent analytical results of Fralick and Forney (1991).

II. Thermocouple Fabrication

A supported thermocouple wire shown in figure 1 consists of a small diameter thermocouple element (horizontal wire) mounted on two large diameter supported wires (vertical wires). The large diameter support wires are mounted in a ceramic stick that assumes the mean gas temperature $T_{0}$. Since a supported thermocouple is normally constructed manually, there are a number of physical imperfections that can affect the response. For example, three joints must be fabricated consisting of the thermocouple junction and joints at both ends of the thermocouple element. These three joints (welded or soldered) and the epoxy used to secure the support legs in the ceramic stick are darkened in the schematic at the bottom of figure 1. As indicated in figure 1, the supported thermocouple may not be symmetrical and there may be additional material or beads at the joint locations.

\section{Physical Dimensions}

The thermocouple support wires and the smaller thermocouple elements were analyzed by Elmore et al. (1983) for stresses at the maximum flow conditions for the 
F100 gas turbine engines of $\mathrm{T}=1680^{\circ} \mathrm{K}, \mathrm{P}=2.01 \times 10^{6}$ Newton $/$ meter $^{2}$ (292 psia)

and a gas March number $M=0.36$. The sensor location for these calculations corresponded to a wall position between the vanes downstream of the combustor exit. Elmore et al. (1983) also assumed an allowable stress in the thermocouple wire of $4.39 \times 10^{7} \mathrm{Newton} /$ meter $^{2}(6360 \mathrm{psi})$. The maximum allowable length-to-diameter ratio L/D for the support wire was thus calculated to be 6.5 while the maximum value for the thermocouple element was found to be 15.5 .

Elmore et al. (1986) also limited the smallest diameter of the thermocouple wire to $76 \mu m(.003$ in) because of limitations to junction fabrication. These constraints limit the length of the thermocouple element on each side of the junction to roughly $1 \mathrm{~mm}$ or to a total length of $2 \mathrm{~mm}$ for the thermocouple wire suspended between the support legs. Moreover, if the diameter of the supports is $380 \mu \mathrm{m}(.015 \mathrm{in})$, the length of the support legs are limited to roughly $2 \mathrm{~mm}$.

\section{Materials}

In the present study thermocouples are constructed of either type $\mathrm{K}$ (chromelalumel) or type $\mathrm{T}$ (copper-constantan) materials. The properties of these materials including the product of specific heat and wire density $\rho c$ and the thermal diffusivity $\alpha=k / \rho c$ are listed in table 1 . The type $\mathrm{K}$ thermocouple was chosen since one normally assumes that the material properties are equal across the junction. In contrast, the type $\mathrm{T}$ thermocouple has a distinctly different thermoconductivity across the junction. As a result, the temperature profile is asymmetric for the type $T$ 
thermocouple and theoretical expressions derived to predict the frequency response must reflect these features.

The theoretical analysis of a supported thermocouple assumes that the radial temperature gradients in a wire cross section are negligable. In this case the heat conduction is one - dimensional down the axis of the wire. Schematics of both a one and two material supported wire are represented in figure 2. Here, wire diameters and lengths are illustrated and their values are listed in table 1.

The positive lead for both the type $K$ and $T$ thermocouples is positioned on the left of the junction in fig. 2 as indicated at the bottom of table 1. If the material properties are nearly equal across the junction, as is the case for a type $\mathrm{K}$ thermocouple, one can define two natural frequencies for wire regions 1 and 2 in fig. 2 where $\omega_{1}=4 h_{1} / \rho c D_{1}$ and $\omega_{2}=4 h_{2} / \rho c D_{2}$. For the type $T$ thermocouple, however, there are four natural frequencies. For example, two of these frequencies are $\omega_{1}=4 h_{1} / \rho_{1} c_{1} D_{1}$ and $\omega_{2}=4 h_{1} / \rho_{2} c_{2} D_{1}$ on both sides of the junction.

\section{Construction}

Thermocouple wire of the desired length and type was threaded into the ceramic with the thermocouple end last. Three or four kinks were made in each wire near the thermocouple end so the wire must be firmly pulled into the tube leaving enough wire sticking out to make the thermocouple. Drops of epoxy were picked up with a piece of .010 in. diameter wire, added to the ceramic tube at A (see fig. 3) and pushed down around both wires. The kinks and epoxy firmly fasten the 
wires in the ceramic so they do not twist when the free ends are manipulated for electrical connections.

The type $T$ thermocouple junctions at $C$ in fig. 3 were made by silver soldering. The silver solder wire was coated with flux and the end heated with a torch until a drop formed. A twisted pair of thermocouple wires was pushed briefly into the flux coated solder drop. The solder wetted the pair up to where the twist stops. Using a razor blade and tweezers under a microscope, the thermocouple was bent and trimmed until collinear. The silver solder technique was also used to fabricate the chromel alumel (type K) thermocouples.

The junction at $B$ in fig. 3 was made by cutting the large wire about half way through with a razor blade, laying the small diameter wire in the cut, and silver soldering the cut closed. After the solder, the excess wire ends that protrude through the soldered area were bent and broken off to clean up the junction.

For the chromel alumel couples (type $\mathrm{K}$ ), the junction at $\mathrm{C}$ in fig. 3 could also be fabricated using a stored energy spot welder. In this case, the wires were crossed and welded and then trimmed with a razor blade and bent with tweezers under a microscope until collinear.

\section{Experimental Apparatus}

In the present experiment, thermocouple sensors are exposed to a constant 
velocity air stream $(<19 \mathrm{~m} / \mathrm{sec})$ of varying temperature. In particular, the dynamic response of the thermocouple is measured for a square wave temperature profile of varying frequency. A rotating wheel configuration is used to deliver the test air stream to the proposed sensors. A similar experimental apparatus was described in detail by Elmore et al. (1986).

A schematic of the rotating wheel apparatus used in the present experiment is shown in fig. 4. As the wheel rotates, holes pass the two air supply tubes ( $3 / 4$ in. ID copper) that allow slugs of hot $\left(\leq 55^{\circ} \mathrm{C}\right)$ and cold $\left(\sim 30^{\circ} \mathrm{C}\right)$ air to alternately enter a transition tube assembly mounted directly above the rotating wheel. In the transition tube the slugs of hot and cold air coalesce into a single air stream providing roughly a square wave temperature profile covering a range of gas temperature frequencies from roughly 1 to $30 \mathrm{~Hz}$. A $3 / 4$ in. to $1 / 2 \mathrm{in.} \mathrm{smooth} \mathrm{copper}$ adaptor was inserted at the end of the coalescing tube (location of thermocouple) in fig. 4 to increase the air velocity to $18 \mathrm{~m} / \mathrm{sec}$.

The analog temperature signal is digitized with a Data Translation DT-2801 A/D board mounted in an expansion slot of an IBM AT compatible computer as shown in fig. 4. ASYST software was loaded onto the hard disc of the personal computer and this provided a flexible system for data storage, manipulation and display. The true temperature profile of the airstream is measured with a constant current anemometer (TSI 1054-A) and sensor (1226 PI2.5). 
IV. Experimental Procedure

\section{Calibration}

The air velocity at the exit of the coalescing tube in fig. 4 (location of thermocouple) was maintained at roughly 17.5 to $18 \mathrm{~m} / \mathrm{sec}$. The voltage regulator was adjusted such that the temperature of the hot line was maintained at an elevated temperature of $555^{\circ} \mathrm{C}$. One hole of the rotating wheel was positioned in a stationary position over the unheated line. The voltage output from both the thermocouple and constant current anemometer were recorded at the input terminals to the $\mathrm{A} / \mathrm{D}$ board. The true temperature was also recorded with a thermometer suspended in the high velocity air stream. This procedure was repeated for several temperatures with the hole positioned over the hot line covering an air temperature range from $30^{\circ} \mathrm{C}$ to $55^{\circ} \mathrm{C}$. It was found that both type $\mathrm{K}$ and $\mathrm{T}$ thermocouples had a constant calibration factor $\left({ }^{\circ} \mathrm{C} /\right.$ volt $)$ over the small temperature range. The constant current anemometer, however, provided a nonlinear response with the calibration factor varying with air temperature. Thus, a least square curve fit was determined to provide the gas temperature with the anemometer output. The calibration factors described above were then installed on the ASYST data acquisition software.

The thermocouple and constant current anemometer are mounted in the constant velocity air stream with both sensing elements parallel and separated by approximately $1 \mathrm{~mm}$. The period or frequency of the square wave temperature profile is controlled over the range from 1.5 to $30 \mathrm{~Hz}$ with adjustment of the motor 
connected to the rotating wheel shaft.

\section{Data Acquisition}

ASYST software was developed to acquire temperature data sequentially from the thermocouple and constant current anemometer. The data are digitized for two channels at a sampling rate of $512 \mathrm{~Hz}$ per channel for a total sample time of two seconds. An example of the gas temperature profile for a square wave frequency of $2.5 \mathrm{~Hz}$ is illustrated in fig. 5 where the smooth profile is the thermocouple response. After data acquisition, the Fast Fourier Transform (FFT) is taken for each channel. The largest peak (first harmonic) in the amplitude of the FFT is located for each channel which provides the frequency of the temperature profile. The ASYST software also records the amplitude ratio and phase angle between both channels at the first harmonic. In the latter case, the software corrects the phase angle for the conversion delay between channels. The amplitude ratio and phase angle are recorded for each frequency setting of the rotating wheel.

\section{Data Correlation}

Once the amplitude ratio and phase angle are recorded for a large number of gas temperature frequencies $\omega$ for a given thermocouple, the amplitude ratio and phase angle are plotted on separate graphs. Both quantities are plotted as a function of the ratio of the angular frequency of the square wave temperature profile $\omega$ to the natural frequency $\omega_{1}$ of the positive thermocouple element. The natural frequency $\omega_{1}=4 h_{1} / \rho_{1} C_{1} D_{1}$ is chosen to fit the amplitude ratio at large frequencies since the 
amplitude ratio should coincide with the first order response (independent of axial heat conduction) at large $\omega$.

The lengths of the thermocouple element $I$ and support wire $L$ are then chosen such that theoretical predictions of the amplitude ratio are correlated with the data at low gas temperature frequency $\omega$. The remaining parameters representing wire diameters and material properties were recorded from the literature and the manufacture's specifications. These values were also introduced into the analytical expressions used to predict both the amplitude ratio and phase angle.

Theoretical predictions of the amplitude ratio and phase angle are plotted along with the data. For the type $\mathrm{K}$ thermocouples the material properties are assumed to be equal across the junction with the average values of the thermal diffusivity $\alpha$ and the product of the density and heat capacity $\rho c$ listed in table 1 . Predictions of the amplitude and phase angle for the type $\mathrm{K}$ thermocouple were derived from the expression representing the frequency response (Fralick and Forney, 1991)

$$
T(0)=\frac{\frac{1}{G_{2}}\left(\cosh q_{2} L-1\right)-\frac{1}{G_{1}} \cosh q_{2} L}{\cosh q_{1} l \cosh q_{2} L+Q \sinh q_{1} l \sinh q_{2} L}+\frac{1}{G_{1}} .
$$

where

$$
Q=\frac{D_{1}^{2} q_{1}}{D_{2}^{2} q_{2}}
$$


and

$$
q_{n}=\sqrt{\frac{G_{n}}{\gamma_{n}}}, \quad \gamma_{n}=\frac{\alpha}{\omega_{n}}, \quad G_{n}=1+i\left(\omega / \omega_{n}\right), \quad \omega_{n}=\frac{4 h_{n}}{\rho c D_{n}}
$$

Here, the subscripts 1 and 2 refer to the wire elements in the one-material schematic of figure 2 and $T(0)=|T(0)| \exp (i \Phi)$ where $|T(0)|$ is the amplitude ratio and $\Phi$ is the phase angle.

Theoretical predictions of the amplitude ratio and phase angle for the type $T$ thermocouple were derived from the expression

$$
T(0)=\frac{1}{\Delta_{1}}\left\{Q_{t} \sinh q_{2}\left[T_{a}+\frac{1}{G_{1}}\left(\cosh q_{1} l-1\right)\right]+\sinh q_{1} l\left[T_{b}+\frac{1}{G_{2}}\left(\cosh q_{2} l-1\right)\right]\right\}
$$

where

$$
Q_{1}=\frac{k_{1} q_{1}}{k_{2} q_{2}}
$$

and

$$
\Delta_{1}=Q_{1} \cosh q_{1} l \sinh q_{2} l+\cosh q_{2} l \sinh q_{1} l .
$$

The boundary temperatures $T_{a}, T_{b}$ in Eq. (2) are given by the expressions 


$$
\begin{aligned}
& T_{a}=\frac{1}{G_{3}}+\left\{\sinh q_{3} L\left[\left(\frac{1}{G_{4}}-\frac{1}{G_{3}}\right) \cosh q_{4}(l+L)-\frac{1}{G_{4}}\right]\right. \\
& \left.-\frac{1}{G_{3}}\left[Q_{3} \cosh q_{3} l \sinh q_{4}(l+L)+\cosh q_{4}(l+L) \sinh q_{3} l\right]\right\}\left(\frac{1}{\Delta_{2}}\right)
\end{aligned}
$$

and

$$
\begin{aligned}
& T_{b}=\frac{1}{G_{4}}+\left\{Q_{s} \sinh q_{4} L\left[\left(\frac{1}{G_{3}}-\frac{1}{G_{4}}\right) \cosh q_{3}(l+L)-\frac{1}{G_{3}}\right]\right. \\
& \left.-\frac{1}{G_{4}}\left[\cosh q_{4} l \sinh q_{3}(l+L)+Q_{s} \cosh q_{3}(l+L) \sinh q_{4} l\right]\right\}\left(\frac{1}{\Delta_{2}}\right)
\end{aligned}
$$

where

$$
\begin{aligned}
& Q_{s}=\frac{k_{1} q_{3}}{k_{2} q_{4}} \\
& \Delta_{2}=Q_{s} \cosh q_{3}(l+L) \sinh q_{4}(l+L)+\cosh q_{4}(l+L) \sinh q_{3}(l+L)
\end{aligned}
$$

Here, the wire elements 1 to 4 are shown in the schematic of a two-material thermocouple wire shown in figure 2. 


\section{Results and Discussion}

A type $\mathrm{K}$ thermocouple was silver soldered with a thermocouple element length of $1=1.1 \mathrm{~mm}$ and a support wire length of $\mathrm{L}=2.2 \mathrm{~mm}$. The thermocouple and support wires had diameters of $D_{1}=76 \mu \mathrm{m}$ and $D_{2}=380 \mu \mathrm{m}$, respectively. The amplitude ratio and phase angle were measured over a range of temperature square wave frequencies of 1.3 to $35 \mathrm{~Hz}$ and these data are plotted in figure 6. The data are also compared with the theoretical predictions derived from Equation (1).

A value of the natural frequency $\omega_{1}$ was chosen to correlate the data when $\omega / \omega_{1}>1$. The value of $\omega_{1}$ chosen was within $10 \%$ of the predicted value based on the air velocity and thermocouple wire diameter. As indicated in figure 6 , all of the data are correlated with the theory to within $10 \%$. It should also be noted that a small bead did exist at the junction with a diameter less than twice the diameter of the thermocouple element wire. Moreover, the attenuation of the signal because of axial heat conduction is properly accounted for with the theory.

A type $\mathrm{T}$ thermocouple junction was purchased from Omega Engineering and the thermocouple wire was silver soldered at the support legs. This thermocouple had an element length of $1=1.5 \mathrm{~mm}$ and a support wire length of $2.2 \mathrm{~mm}$. The thermocouple and support wires had diameters of $D_{1}=76 \mu \mathrm{m}$ and $D_{2}=380 \mu \mathrm{m}$, respectively. The amplitude ratio and phase angle were measured over a range of temperature square wave frequencies of 1.3 to $30 \mathrm{~Hz}$ and these data are plotted in figure 7. The data are also compared with the theoretical predictions derived from 
Equation (2).

A value of the natural frequency $\omega_{1}=20 \sec ^{-1}$ was chosen to correlate the data for the amplitude ratio at large frequencies $\omega / \omega_{1}>1$. As indicated in figure 7 , the data for the amplitude ratio drift below the theoretical prediction by $10 \%$ for increasing gas temperature angular frequencies $\omega$. Although the effect of axial heat conduction is properly accounted for in figure 7, the phase angle data also appear to be distorted and to lie significantly below the predictions. These effects are apparently due to the large bead diameter at the junction that is greater than twice the diameter of the thermocouple wire.

A type $\mathrm{T}$ thermocouple junction was constructed with silver solder on a twisted pair of thermocouple wires. The junction consisted of a twisted pair of soldered thermocouple wires $1.0 \mathrm{~mm}$ in length that was bent perpendicular to the axis of the wire elements suspended between the support legs. The wire element length was $\mathrm{l}=1.5 \mathrm{~mm}$ and the length of the support leg was $\mathrm{L}=2.2 \mathrm{~mm}$, as before. This thermocouple configuration was constructed to determine the effect of the bead size on the frequency response.

The amplitude ratio and phase angle for the beaded type $T$ thermocouple are plotted in figure 8. As indicated in figure 8 , the amplitude is larger than predicted at low frequencies since the extended exterior surface of the bead (fin) enhances the rate of heat transfer to the junction. At large frequencies, $\omega / \omega_{1}>1$ however, the smaller area - to - volume ratio decreases the natural frequency of the bead 
configuration relative to a beadless cylinder and the amplitude data fall below the theory. More difficult to describe is the distortion in the phase angle data. As indicated in figure 8 , the phase angle is shifted to larger values relative to the theory.

\section{Conclusions}

Supported type $\mathrm{K}$ and type $\mathrm{T}$ thermocouple wires were constructed. The thermocouple element $(D=76 \mu \mathrm{m})$ and wire support $(D=380 \mu \mathrm{m})$ lengths were approximately 1.0 and $2.0 \mathrm{~mm}$, respectively. Measurements of the amplitude ratio and phase angle that reflect the effects of axial heat conduction are correlated to within $10 \%$ with the theoretical predictions of Fralick and Forney (1991). To correlate the experimenal data, it is necessary to choose a natural frequency $\omega_{n}$ (depends on gas properties and velocity) for the amplitude data at large gas temperature frequencies and to adjust the wire lengths that appear in the theory.

The use of silver solder for the junction and wire supports is adequate for both the type $\mathrm{K}$ and type $\mathrm{T}$ thermocouples. A spot welding procedure for the type $\mathrm{K}$ thermocouple, however, appears to introduce a large contact resistance since the measured amplitude ratio in this case was only a fraction of its predicted value.

It is found that a large bead at the thermocouple junction increases the amplitude ratio at low frequencies but decreases the natural frequency of the wire. The phase angle data are also distorted for imperfect junctions. 


\section{Nomenclature}

$$
\begin{array}{lll}
\mathrm{C} & = & \text { material specific heat }\left(J-g m^{-1}-{ }^{0} K^{-1}\right) \\
\mathrm{D} & = & \text { thermocouple wire diameter }(\mathrm{cm}) \\
\mathrm{G} & = & 1+i\left(\omega / \omega_{n}\right) \\
\mathrm{h} & = & \text { heat transfer coefficient }\left(J-\mathrm{cm}^{-2}-\mathrm{s}^{-1}-{ }^{0} K^{-1}\right) \\
\mathrm{i} & = & \text { unit imaginary number }(=\sqrt{-1}) \\
\mathrm{k} & = & \text { material thermoconductivity }\left(J-c m^{-1}-\mathrm{s}^{-1}-{ }^{0} K^{-1}\right) \\
\mathrm{l} & = & \text { length of small thermocouple element wire }(\mathrm{cm}) \\
\mathrm{L} & = & \frac{D_{1}^{2} q_{1}}{D_{2}^{2} q_{2}} \\
\mathrm{Q} & = & \frac{k_{1} q_{1}}{k_{2} q_{2}} \\
\mathrm{Q} & = & \frac{k_{1} q_{3}}{k_{2} q_{4}} \\
\mathrm{~T} & = & (G / \gamma)^{5} \\
\mathrm{X} & = & \text { steady-state frequency response } \\
\mathrm{Q}_{\mathrm{s}} & = &
\end{array}
$$

Greek Symbols
$\alpha \quad=$
thermal diffusivity $\left(\mathrm{cm}^{2}-\mathrm{s}^{-1}\right)$ 


$\begin{array}{lll}\gamma & = & \alpha / \omega_{n}\left(\mathrm{~cm}^{2}\right) \\ \omega & = & \text { angular frequency }\left(s^{-1}\right) \\ \omega_{n} & = & \text { natural frequency of wire }(=4 \mathrm{~h} / \rho \mathrm{cD})\left(\mathrm{s}^{-1}\right) \\ \Phi & = & \text { phase angle } \\ \rho & = & \text { material density }\left(\mathrm{gm} / \mathrm{cm}^{3}\right) \\ \Delta_{1} & = & \text { dimensionless function } \\ \Delta_{2} & = & \text { dimensionless function }\end{array}$


VIII. References

1. Dils, R. R. and Follansbee, P. S., Wide Bandwidth Gas Temperature Measurements in Combustor and Combustor Exhaust Gases, Instrumentation in the Aerospace Industry 21 (B. Washburn, ed.), ISA 76245 (1976).

2. Elmore, D. L., Robinson, W. W. and Watkins, W. B., Dynamic Gas Temperature Measurement System: Final Report, NASA CR-168267 (1983).

3. Elmore, D. L., Robinson, W. W. and Watkins, W. B., Further Development of the Dynamic Gas Temperature Measurement System: Vol. I - Technical Efforts, NASA CR-179513 (1986).

4. Forney, L. J. and Fralick, G. C., Frequency Response of a Thermocouple Wire: Effects of Axial Heat Conduction, Int. Comm. Heat Mass Transfer, 18, 531(1991).

5. Fralick, G. C., Correlation of Velocity and Velocity-Density Turbulence in the Exhaust of an Atmospheric Burner, Turbine Engine Hot Section Technology 1985, NASA CP-2465, pp. 81-85.

6. Fralick, G. C. and Forney, L. J., and Frequency Response of a Supported Thermocouple Wire: Effects of Axial Heat Conduction (submitted, International I. Heat and Mass Transfer, 1991).

7. Scadron, M.D. and Warshawsky, I., Experimental Determination of Time Constants and Nusselt Numbers for Bare-Wire Thermocouples in High Velocity Air Streams and Analytic Approximation of Conduction and Radiation Errors, NACA TN-2599 (1952).

8. Touloukian, Powell, Ho and Clements, (ed.), Thermal Physical Properties of Matter, Purdue Research Foundation, Plenum Pub. (1970). 
Table 1 Properties of Thermocouples

Dimensions $(\mathrm{cm})$

$\begin{array}{lcccc}\underline{\mathrm{D}}_{1} & \underline{\mathrm{D}_{2}} & \underline{\mathrm{D}_{2}} / \mathrm{D}_{1} & \underline{1} & \underline{\mathrm{L}} \\ .0076 & .038 & 5 & .1-.15 & .17-.22\end{array}$

Properties of Type K

$$
\rho c\left[\frac{J}{\mathrm{~cm}^{3}-K}\right] \quad \alpha\left[\frac{\mathrm{cm}^{2}}{\mathrm{sec}}\right]
$$

Chromel

3.80

.048

Alumel

4.10

.070

Average

3.95

.059

\section{Properties of Type T}

$$
\rho c\left[\frac{J}{\mathrm{~cm}^{3}-\mathrm{O} K}\right] \quad \alpha\left[\frac{\mathrm{cm}^{2}}{\mathrm{sec}}\right]
$$

$\begin{array}{lll}\text { Copper } & 3.44 & 1.16 \\ \text { Constantan } & 3.48 & .067 \\ \text { Average } & 3.46 & .614\end{array}$

$\underline{\text { Wire Location }}$

Region

left

right
Type K

Chromel

Alumel
Type T

Copper

Constantan 


\section{SUPPORTED THERMOCOUPLE}

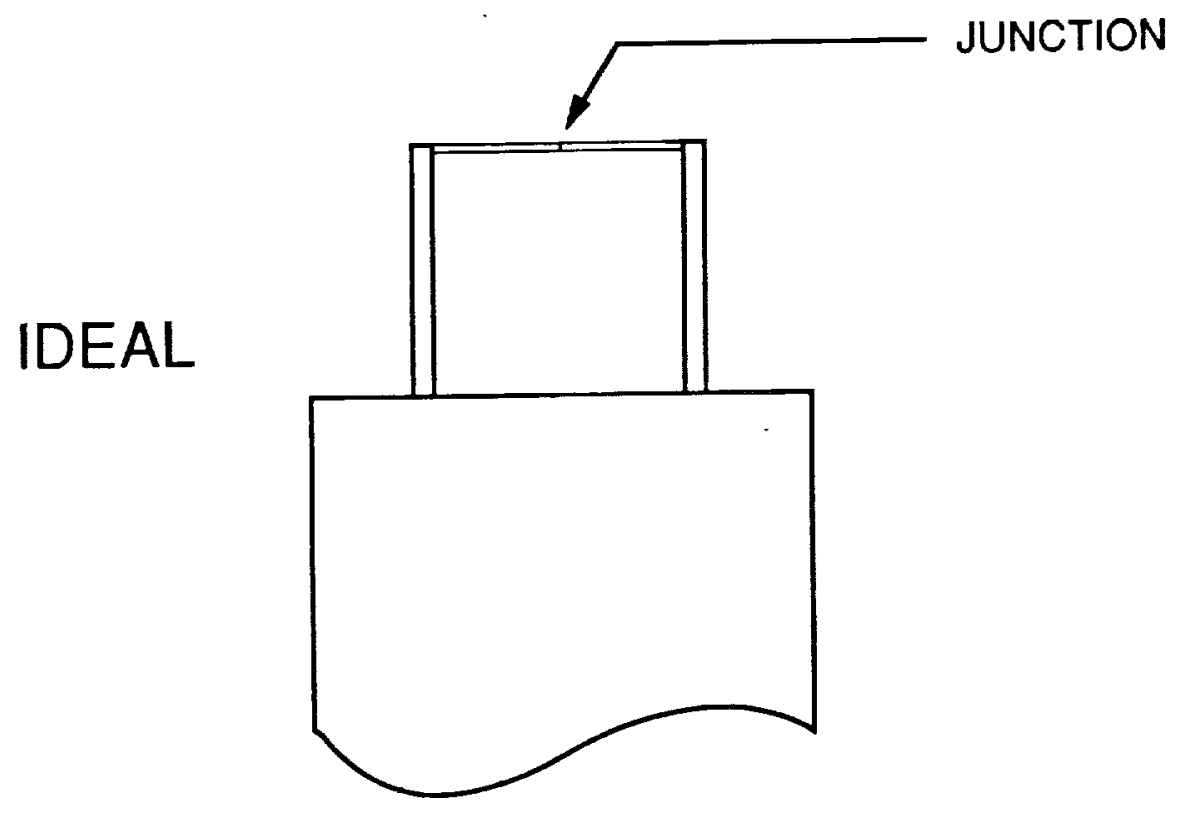

NON-IDEAL

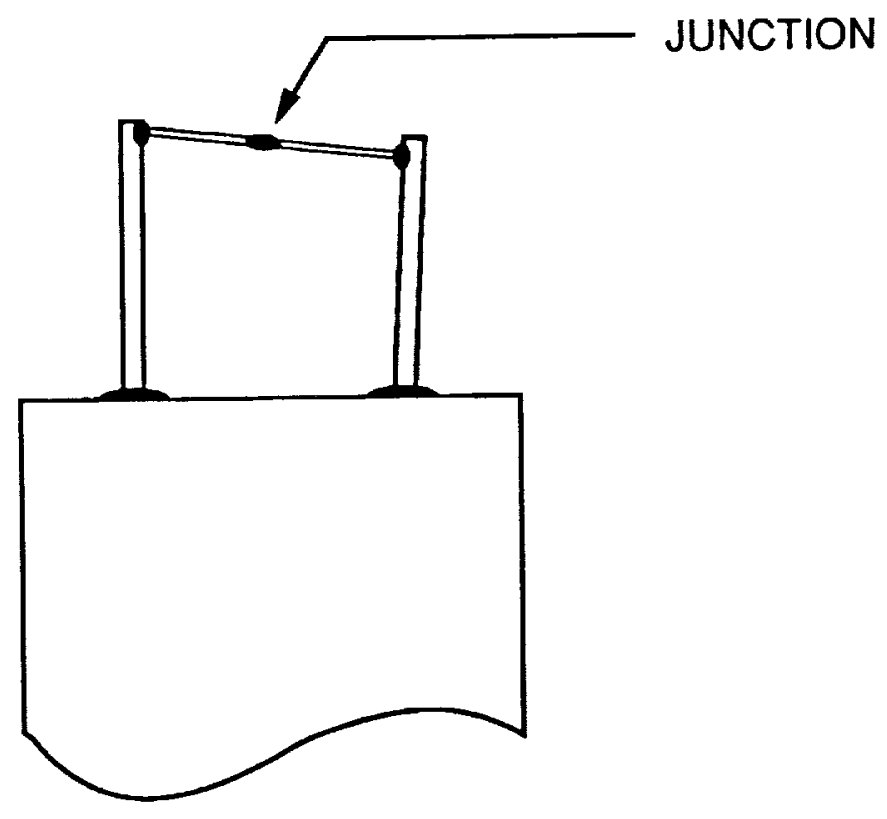

1. Schematic of Supported Thermocouple 


\section{Fluid Flow}
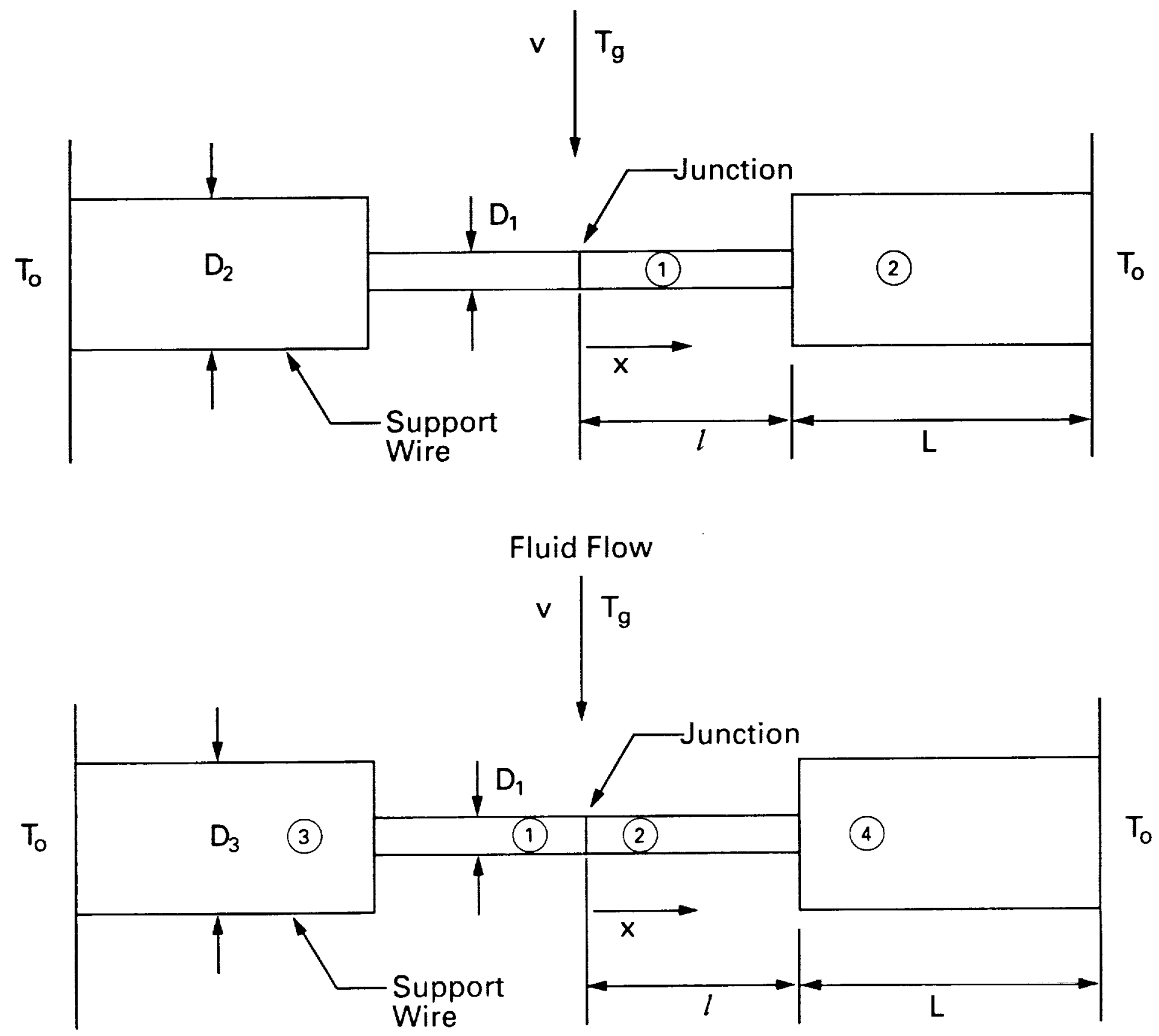

2. Schematic of One or Two Material Supported Wires 


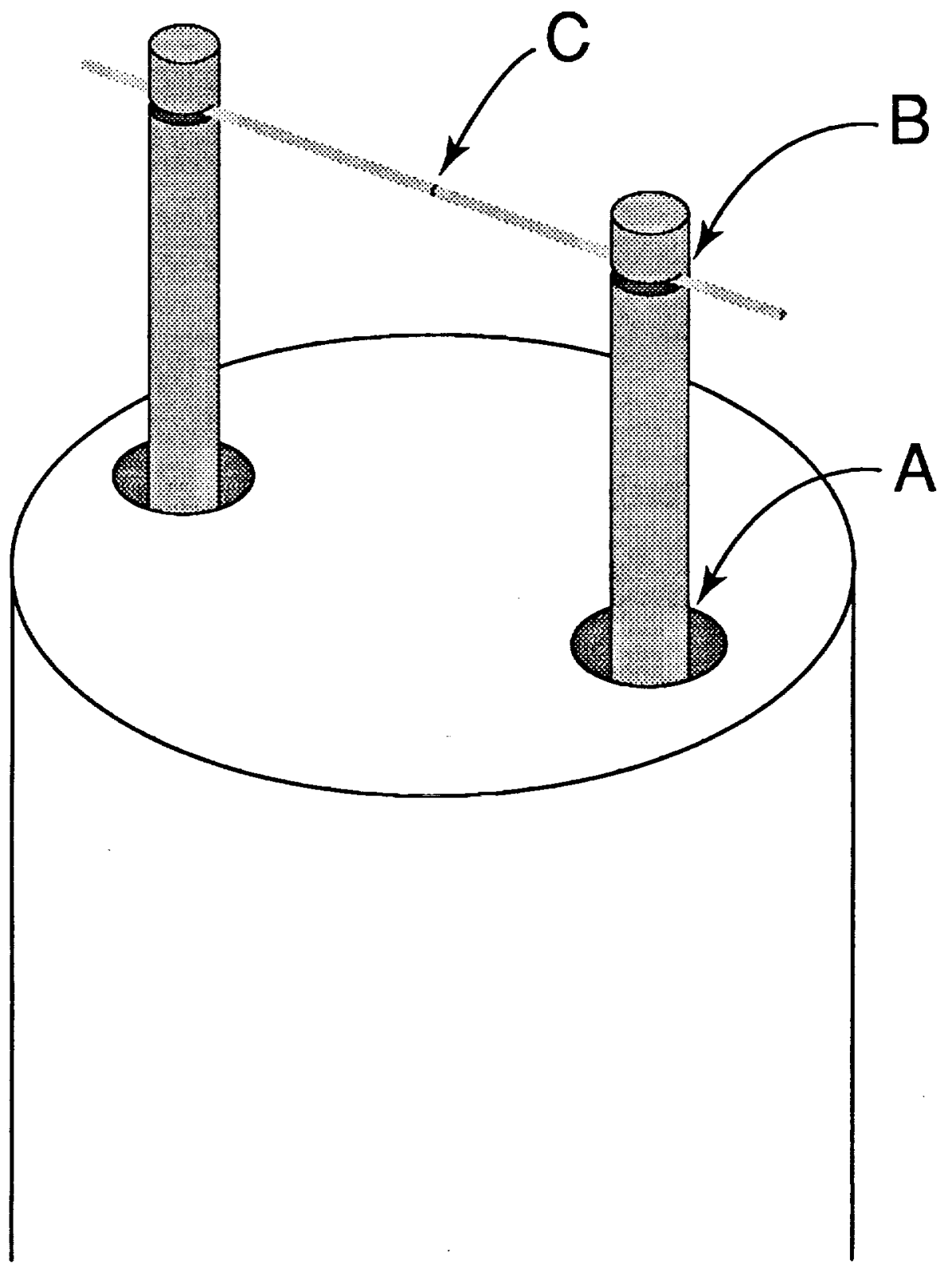

3. Configuration of Test Thermocouple 


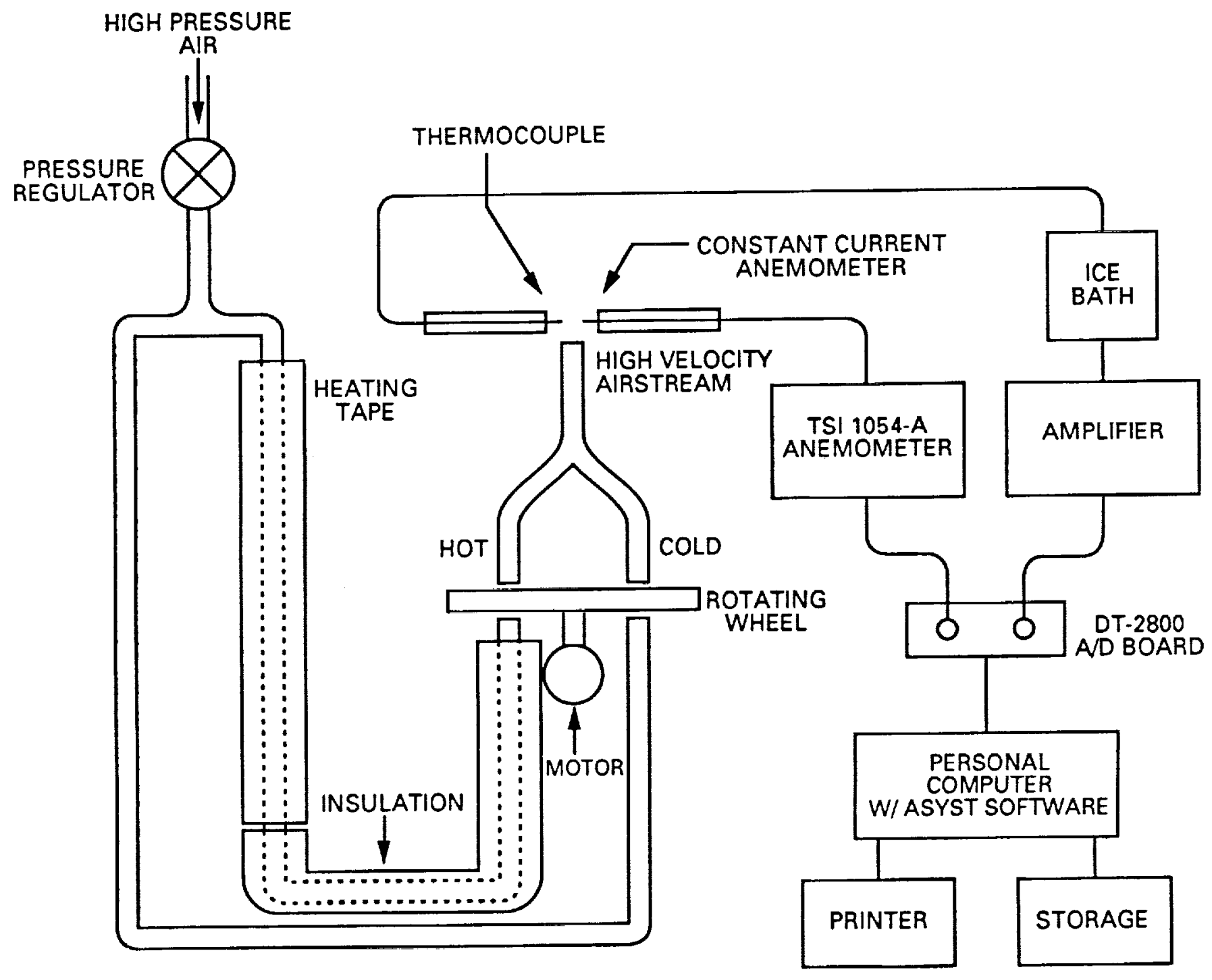

4. Schematic of Rotating Wheel Apparatus 


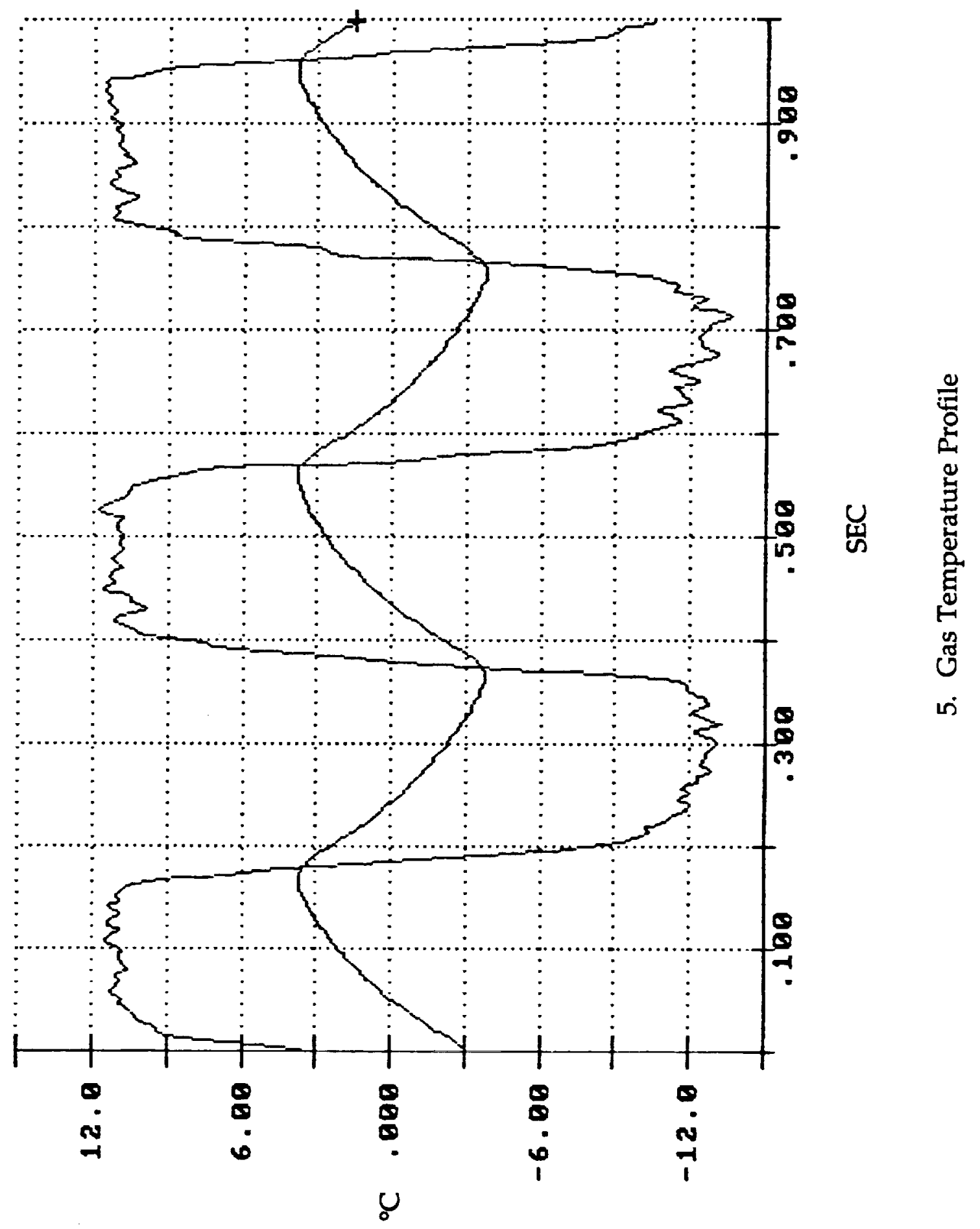



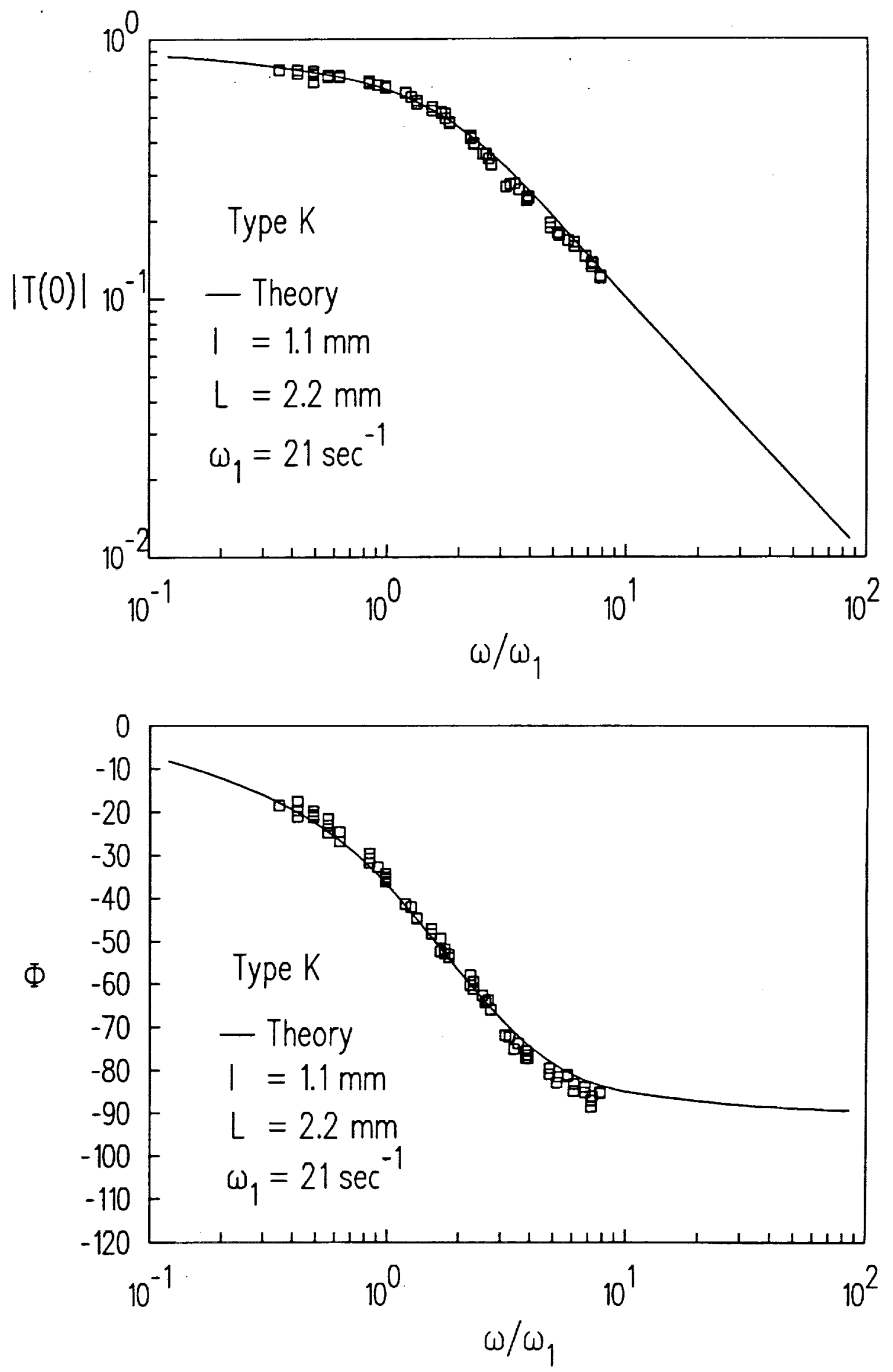

6. Amplitude Ratio and Phase Angle vs. Gas Temperature Frequency 

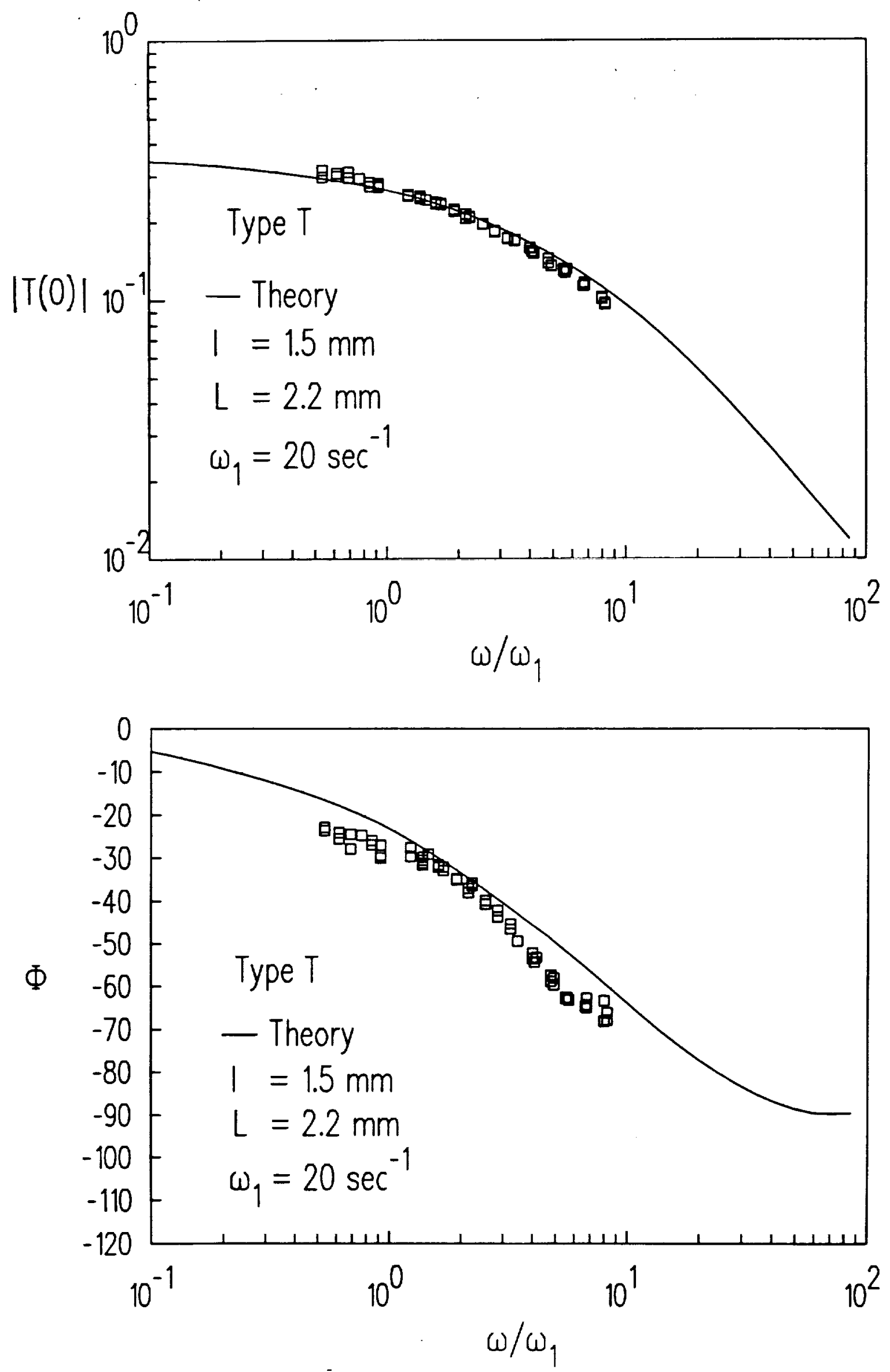

7. Amplitude Ratio and Phase Angle vs. Gas Temperature Frequency 

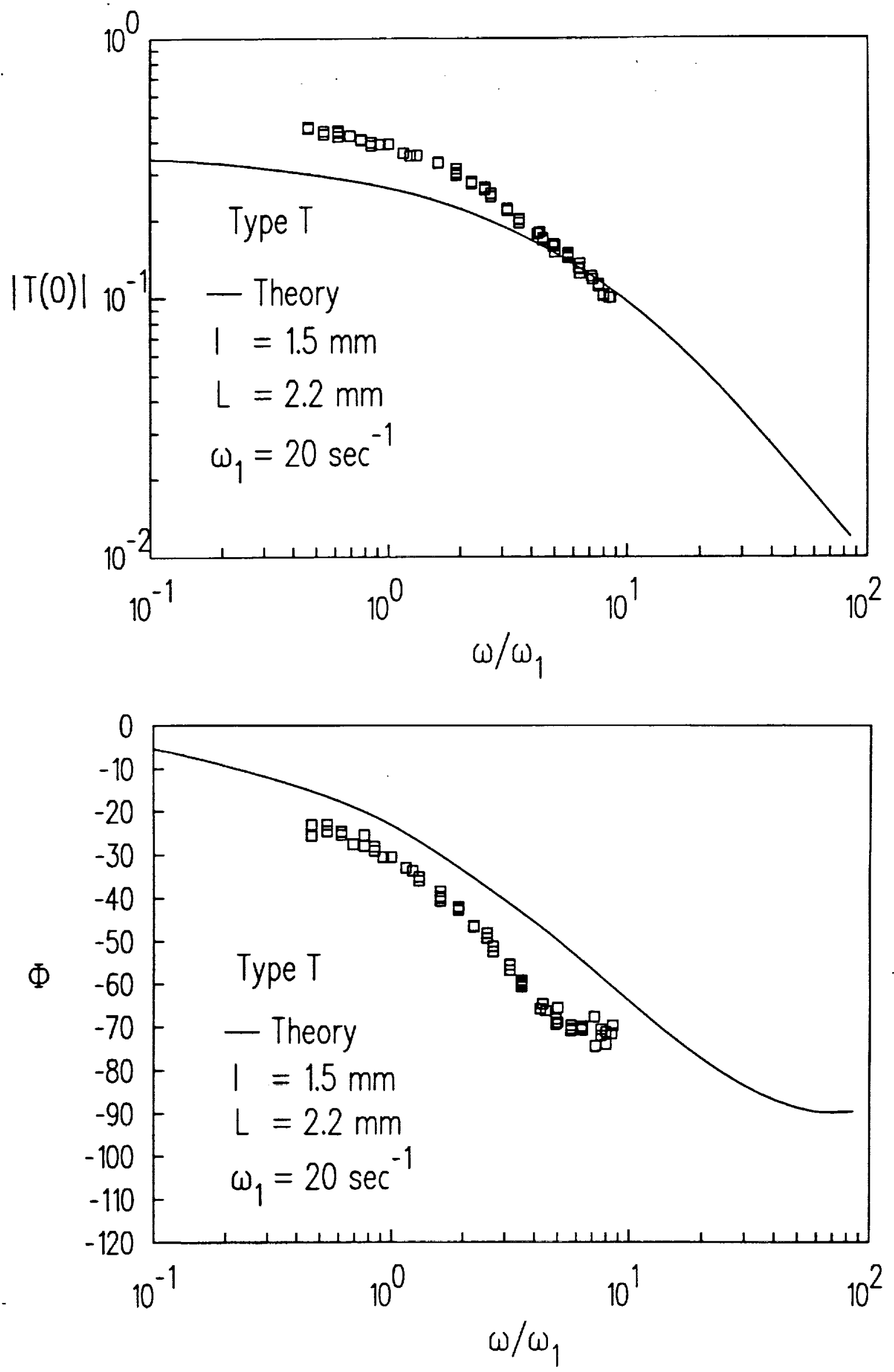

8. Amplitude Ratio and Phase Angle vs. Gas Temperature Frequency for Thermocouple with Large Bead. 